\title{
Molecular Requirements for Self-Interaction of the Respiratory Syncytial Virus Matrix Protein in Living Mammalian Cells
}

\author{
Marta Trevisan 1,+ ${ }^{+}$Veronica Di Antonio 1,+ ${ }^{\text {, Annalisa Radeghieri }}{ }^{2}$ (D), Giorgio Palù ${ }^{1}$, \\ Reena Ghildyal ${ }^{3, *}$ and Gualtiero Alvisi ${ }^{1, * \text { (D) }}$ \\ 1 Department of Molecular Medicine, University of Padua, Padua 35121, Italy; marta.trevisan@unipd.it (M.T.); \\ veronicadiantonio@libero.it (V.D.A.); giorgio.palu@unipd.it (G.P.) \\ 2 Department of Molecular and Translational Medicine, University of Brescia, Brescia 25123, Italy; \\ annalisa.radeghieri@unibs.it \\ 3 Centre for Research in Therapeutic Solutions, Faculty of Science and Technology, University of Canberra, \\ Canberra 2617, Australia \\ * Correspondence: Reena.Ghildyal@canberra.edu.au (R.G.); gualtiero.alvisi@unipd.it (G.A.) \\ + These authors contributed equally to this work.
}

Received: 9 February 2018; Accepted: 28 February 2018; Published: 3 March 2018

\begin{abstract}
Respiratory syncytial virus (RSV) is an important human pathogen, which infects respiratory tract epithelial cells causing bronchiolitis and pneumonia in children and the elderly. Recent studies have linked RSV matrix (M) ability to self-interaction and viral budding. However, RSV M has been crystalized both as a monomer and a dimer, and no formal proof exists to date that it forms dimers in cells. Here, by using a combination of confocal laser scanning microscopy and bioluminescent resonant energy transfer applied to differently tagged deletion mutants of RSV $\mathrm{M}$, we show that the protein can self-interact in living mammalian cells and that both the $\mathrm{N}$ and C-terminus of the protein are strictly required for the process, consistent with the reported dimeric crystal structure.
\end{abstract}

Keywords: RSV M protein; virus assembly; Bioluminescence resonance energy transfer (BRET); confocal microscopy

\section{Introduction}

Respiratory syncytial virus (RSV) is the major cause of lower respiratory tract disease in infants and young children [1-3], responsible for one-third of deaths resulting from acute lower respiratory infection in the first year of life [4-6]. RSV also causes severe respiratory tract disease in immunosuppressed and older adults, leading to substantial annual mortality [7]. There are no vaccines or antiviral drugs that effectively target RSV despite decades of research [8]. Deeper understanding of the molecular mechanisms that underlie RSV assembly could pave the way to the identification of new vaccine/antiviral targets.

RSV is an enveloped virus with a non-segmented negative sense RNA genome and belongs to the Orthopneumovirus genus of the Pneumoviridae family [9]. The RSV genome is tightly encapsidated within the nucleocapsid, which is composed of nucleocapsid protein $\mathrm{N}$, the RNA polymerase $\mathrm{L}$ and its cofactor phosphoprotein P, as well as the M2-1 protein. External to the nucleocapsid is a layer of matrix $(\mathrm{M})$ protein which acts as a bridge between the nucleocapsid and the lipid bilayer envelope. Embedded in the envelope are the fusion $(\mathrm{F})$, large $(\mathrm{G})$ and small hydrophobic $(\mathrm{SH})$ glycoproteins. M2-2, NS1 and NS2 proteins are not found in the virion in any significant amount but have important roles in the RSV replication cycle [10-15]. 
M protein is a major structural protein of RSV, playing a central role in virus assembly and in retaining the intact virion [16]. M interacts with the envelope glycoproteins [17-20], with the nucleocapsids [21-24] and with the host membrane [19,25,26] to facilitate assembly. $M$ has been postulated to bring the nucleocapsids and envelope glycoproteins together through its ability to oligomerise $[27,28]$. This is an essential assembly step to ensure production of infectious virus. Previous studies have shown that $M$ readily forms homodimers and self-aggregates in vitro [19,28,29]. Despite the harsh ionic conditions required to isolate $M$ in its monomeric form [19], $M$ was at first crystallized as a monomer [26] and later shown to form dimers [27], similarly to matrix proteins from other Mononegavirales, including other Penumoviridae members such as human Metapneumovirus [27,30-33]. Based on the in vitro data and on observations of mutant $M$ in the context of infected and transfected cells, it was postulated that $\mathrm{M}$ can form oligomers in cells, however this had not been shown experimentally. Mutations targeting the dimerization interface affected the ability to form virus-like particles in a co-transfection system, but this did not correlate with loss of dimerization as assessed by size exclusion chromatography [27], raising the possibility that the observed phenotype was due to misfolding or aggregation of $\mathrm{M}$.

In this study, we have used confocal laser scanning microscopy (CLSM) and bioluminescent resonant energy transfer (BRET) in cells transfected to express differently tagged $\mathrm{M}$, to show that $\mathrm{M}$ can self-interact in live cells and that both $\mathrm{N}$ and $\mathrm{C}$ termini are required for this interaction. Our findings confirm and extend previous in vitro data on $\mathrm{M}$ oligomerization. Importantly, our studies validate the published structure of the $\mathrm{M}$ dimer that predicts a direct interaction between $\mathrm{N}$ and $\mathrm{C}$ termini of two monomers to form the dimer [27].

\section{Materials and Methods}

\subsection{Plasmid Construction}

Mammalian expression plasmids were generated using the Gateway ${ }^{\mathrm{TM}}$ technology (Invitrogen, Carlsbad, CA, USA). Entry clones pDNR207-M (1-256), pDNR207-M (1-200), pDNR207-M (110-183) and PDNR207-M (183-256) were generated via BP recombination reactions between PCR products with attB sites flanking the appropriate coding sequences and plasmid pDNR207 (Life Technologies, Carlsbad, CA, USA, as described previously [34]), using the full-length codon optimized M gene cloned into pCDNA3.1 [27] as a template.

Entry clones were used to generate C-terminal yellow fluorescent protein (YFP), cyan fluorescent protein (CFP) and Renilla luciferase (RLuc) fusion Mammalian expression vectors following LR recombination reactions with the pDESTnYFP, pDESTnCFP and pDESTnRLuc [35] Gateway compatible vectors, as described in [36]. All vectors were confirmed by sequencing.

\subsection{Cell Culture and Transfections}

Human embryonic kidney (HEK)293-A and HEK293-T cells were maintained in Dulbecco's modified Eagle's medium (DMEM) supplemented with 10\% $(v / v)$ fetal bovine serum (FBS), $50 \mathrm{U} / \mathrm{mL}$ penicillin, $50 \mathrm{U} / \mathrm{mL}$ streptomycin and $2 \mathrm{mM}$ L-glutamine as described in [37]. For imaging experiments, cells were trypsinized and $2.5 \times 10^{4}$ HEK293-A cells were seeded onto polylysinated $12 \mathrm{~mm}$ glass coverslips in 24-well plates 1 day before transfection [38]. Each well was transfected with a total of 250 ng of plasmid DNA and $1 \mu \mathrm{L}$ of lipofectamine 2000 (Thermofisher, Waltham, MA, USA).

For BRET experiments, cells were trypsinized and $1 \times 10^{5}$ HEK293-T cells were seeded onto 24-well plates 1 day before transfection [39]. Each well was transfected with a total of $500 \mathrm{ng}$ of plasmid DNA and $2 \mu \mathrm{L}$ of lipofectamine 2000 (Thermofisher). BRET saturation experiments were performed transfecting cells with $0.5 \mathrm{ng}$ of RLuc-M (1-256) and increasing amounts (0-450 ng) of YFP-M (1-256). Total DNA amount was normalized to $500 \mathrm{ng}$ total with plasmid pCDNA3.1 (Thermofisher, Waltham, MA, USA). Importantly, no signs of cell toxicity were observed upon transfection of all M expression plasmids. 


\subsection{Microscopy/CLSM/Image Analysis}

Subcellular localization of fluorescently tagged fusion proteins was visualized $24 \mathrm{~h}$ and $48 \mathrm{~h}$ after transfection using an inverted epi-fluorescent microscope (Leica, Wetzlar, Germany) equipped with a $40 \times$ objective, essentially as described previously [40]. $48 \mathrm{~h}$ after transfection, cells were fixed with $4 \%$ paraformaldehyde $15 \mathrm{~min}$ at room temperature (RT), before being mounted onto glass coverslips with FluoromountG (Southern Biotech, Birmingham, AL, USA). When required nuclei where counterstained with DRAQ5 (Life Technologies, Carlsbad, CA, USA, 1:1000). Samples were processed by confocal laser scanning microscopy (CLSM) using a Leica TCT-SP2 system, equipped with a Planapo fluor $63 \times$ oil immersion objective (Leica). The Fn/c values were determined using the NIH ImageJ 1.62 public domain software, from single cell measurements for each of the nuclear $(\mathrm{Fn})$ and cytoplasmic $(\mathrm{Fc})$ fluorescence, subsequent to the subtraction of fluorescence due to autofluorescence/background as described previously [41]. Co-localization analysis was performed using the coloc2 plugin. Data were plotted and analyzed using Prism 6 (GraphPad) software (La Jolla, CA, USA).

\subsection{Bioluminescence Resonance Energy Transfer (BRET) Assays}

BRET experiments were performed as described in [35]. Briefly, 293T cells were transfected in 24-well plates with appropriate amounts of BRET donor expressing plasmids. For each construct, the donor (RLuc) expressing plasmid was transfected either in the absence or in the presence of the relative acceptor (YFP) expressing plasmid to allow calculation of background BRET signal. $48 \mathrm{~h}$ post transfection, culture media was removed from wells and cells were very gently washed with $1 \mathrm{~mL}$ of PBS, before being resuspended with $290 \mu \mathrm{L}$ of fresh PBS. Cells were further resuspended and $90 \mu \mathrm{L}$ of mixture were transferred to a black bottomed 96-well plate (Costar ${ }^{\circledR}$, Washington, DC, USA, product number 3916) well in triplicate, and signals acquired using a spectrometer compatible with BRET measurements (VICTOR X2 Multilabel Plate Reader, PerkinElmer, Waltham, MA, USA). Fluorescent signal (YFPnet) relative to YFP fluorescent emission were acquired using a fluorimetric excitation filter (band pass $485 \pm 14 \mathrm{~nm}$ ) and a fluorimetric emission filter (band pass $535 \pm 25 \mathrm{~nm}$ ). Luminometric readings were performed at $5^{\prime}, 15^{\prime}, 30^{\prime}, 45^{\prime}$ and $60^{\prime}$ after addition of the substrate (native Coelenterazine or Coelenterazine-h, depending on the assay, $5 \mu \mathrm{M}$ PJK, Kleinblittersdorf, Germany). Data were acquired for $1 \mathrm{~s} /$ well, using a luminometric $535 \pm 25 \mathrm{~nm}$ emission filter (YFP signal) and a luminometric $460 \pm 25 \mathrm{~nm}$ emission filter (RLuc signal). Before reading, the plate was shaken for $1 \mathrm{~s}$ at normal speed and with double orbit. After background subtraction using values relative to mock transfected cells, the data obtained were used to calculate the BRET signal, defined as the ratio between the YFP and RLuc signals calculated for a specific BRET pair, according to the formula:

$$
\text { BRET signal }=\frac{\text { YFP signal }}{\text { RLuc signal }}
$$

Similarly, the BRET ratio, defined as the difference between the BRET value relative to a BRET pair and the BRET value relative to the BRET donor alone, was calculated according to the formula:

$$
\text { BRET ratio }=\frac{\text { YFP signal }}{\text { RLuc signal }} \text { BRET pair }-\frac{\text { YFP signal }}{\text { RLuc signal }} \text { BRET donor }
$$

BRET saturation curves were then calculated using the GraphPad Prism software by plotting each individual BRET ratio value to the YFPnet/RLuc signal, and interpolating such values using the one-site binding hyperbola function of GraphPad Prism. Specific BRET pairs generate logarithmic shaped curves and reach a plateau. This allowed calculation of BRETmax (Bmax) and $\operatorname{BRET}_{50}\left(\mathrm{~B}_{50}\right)$ values, indicative of maximum energy transfer and relative affinity of the BRET pair tested. 


\subsection{Visualization of RSV M crystal structures}

PDB file $42 \mathrm{~V} 3$ was downloaded from the protein data bank website and Molecular graphics and analyses were performed with the UCSF Chimera package [42]. Chimera is developed by the Resource for Biocomputing, Visualization, and Informatics at the University of California, San Francisco (supported by NIGMS P41-GM103311).

\section{Results}

\subsection{Deletion of N-and C-Terminal Portions of RSV M Affects Protein Subcellular Localization}

We aimed to investigate whether M exists as a dimer/oligomer within cells, and which protein domains are involved in dimerization. We initially analyzed the subcellular localization of several RSV M deletion mutants as expressed in Mammalian cells when C-terminally fused to YFP and CFP. Such fusions included: full-length (FL) M (1-256); M (1-200), lacking a C-terminal loop (L5) involved in formation of dimeric structures by interacting with $\mathrm{N}$-terminal helix $\mathrm{H} 2$ and loop L2, as well as the most extreme C-terminal residues of M nuclear export signal (NES): aas 194-206); M (110-183), containing only the nuclear localization signal (NLS) and DNA binding domain (DBD) (NLS/DBD, residues 110-183), along with a $\alpha$-sheet (S4) involved in protein dimerization by interacting with loop L5, but lacking all other functional elements; M (183-256), retaining only the C-terminal NES and loop L5 (Figure 1).

When expressed individually, the proteins differentially distributed within the cells (Figure 2A,B). YFP-M (1-256) localized mainly in the cytosol, with only very faint nuclear staining $(\mathrm{Fn} / \mathrm{c}=0.26 \pm 0.12)$, consistent with the presence of a strong, chromosomal maintenance 1 (CRM-1) dependent NES, with a punctate pattern reminiscent of ER/Golgi trafficking. The subcellular localization of YFP-M (1-200) was similar to that of YFP-M (1-256), with the exception that a higher fraction of the protein localized to the nucleus $(\mathrm{Fn} / \mathrm{c}=0.38 \pm 0.12)$, and with the fact that the punctate staining was evident in a lower percentage of cells, most likely due to lower expression levels. The difference in the nuclear distribution of YFP-M (1-200) compared to FL M is probably due to the presence of the NLS and the partial loss of the NES (see Figure 1A). Removal of M N-terminal domain resulted in YFP-M (183-256) localizing mainly to the cytosol ( $\mathrm{Fn} / \mathrm{c}=0.34 \pm 0.12)$, mainly with a diffuse pattern, consistently with the presence of a functional NES. On the other hand, YFP-M (110-183), accumulated to the nucleus to higher extent as compared to the other $\mathrm{M}$ fusions, in accordance with the complete deletion of M NESs (Fn/c = 0.9). 

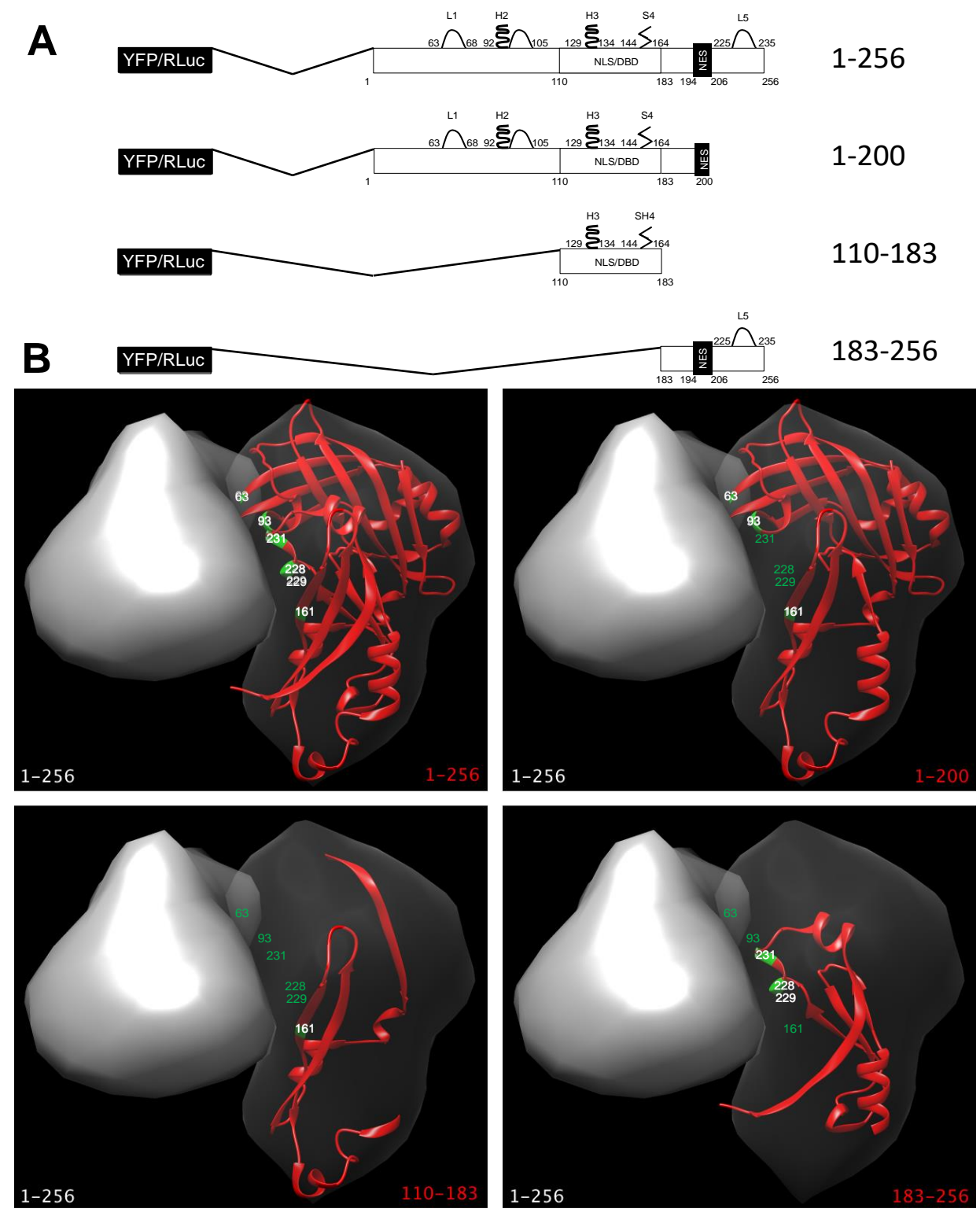

Figure 1. M deletion mutants used in this study (A) Schematic representation of R espiratory syncytial virus (RSV) matrix (M) deletion mutants used in this study as fused to either YFP, RLuc and cyan fluorescent protein (CFP). Elements involved in dimerization are shown, based on the nomenclature used in [26]. L1, loop 1 (aas 63-88); H2, helix 2 and downstream loop (aas 92-105); H3, helix 3 (aas 129-134); S4, sheet 4 (aas 144-163); L5, loop 5 (225-235); NLS/DBD, nuclear localization sequence/DNA binding domain (residues 110-183); NES, nuclear export sequence (aas 194-206); YFP, yellow fluorescent protein; RLuc, Renilla luciferase; (B) The recently solved M dimeric structure (PDB code 4V23) was used to highlight the key aas involved in $\mathrm{M}$ dimerization and their position relative to each deletion mutant tested in this study, using software Chimera as described in the Materials and Methods section. The surface of a full-length M monomer (1-256) is shown as a grey structure in combination with the M versions used in this study, shown as red ribbons. Key residues involved in dimerization in the latter subunit are shown in green. Residue labels are shown either in white or green, depending on their presence or absence in the corresponding deletion mutant, respectively. 
A

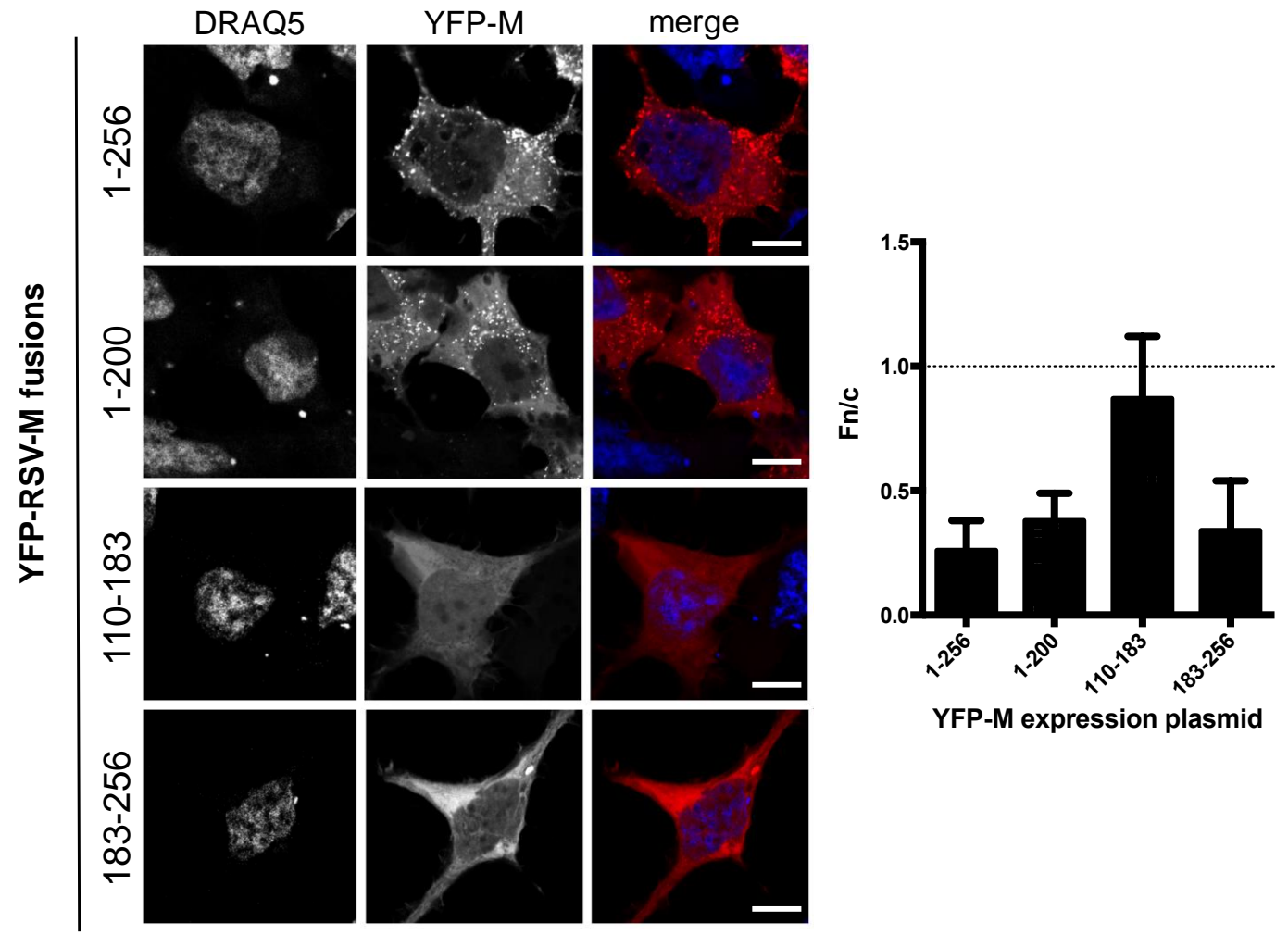

Figure 2. Deletion of N- and C-terminal portions of RSV M affects protein subcellular localization. (A) HEK293 A cells were transfected to transiently express the indicated YFP-M fusions. $24 \mathrm{~h}$ post transfection cell nuclei were stained with DRAQ5, and samples processed for confocal laser scanning microscopy (CSLM) analysis. Representative images relative to cell nuclei (DRAQ5) and M fusions (YFP-M) are shown on the left and middle panels, respectively. Merged images of the two channels are shown in the right panels. Scale bars represent $20 \mu \mathrm{M}$. (B) Digital images such as those shown in (A) were quantitatively analyzed using software ImageJ to calculate the $\mathrm{Fn} / \mathrm{c}$ ratio relative to each fusion protein, as described in Material and Method section. The mean \pm SD relative to at least 75 cells from 2 independent experiments is shown. The dotted line represents Fn/c of 1, corresponding to an even distribution between the nucleus and the cytoplasm.

\subsection{Deletion of $N$ - and C-Terminal Portions of RSV M Affects M's Ability to Colocalize with} Full-Length Protein

We decided to investigate whether the elements involved in dimer formation in vitro [27] were required for $M$ self-interaction in cells. To this end, we expressed CFP-M (1-256) in the presence or in the absence of the M deletion mutants as fused to YFP and investigated the ability of each fusion protein to co-localize, as well as to reciprocally affect each other's subcellular localization. As expected, expression of CFP-M (1-256) resulted in a mainly cytosolic protein, occasionally showing a punctate pattern within the cytosol $(\mathrm{Fn} / \mathrm{c}=0.28 \pm 12)$. Our data indicate that co-expression between CFP-M (1-256) and all YFP-M mutants tested in this study did not affect their reciprocal subcellular localization, as compared to when expressed individually (see Figure 3A-C). 
A
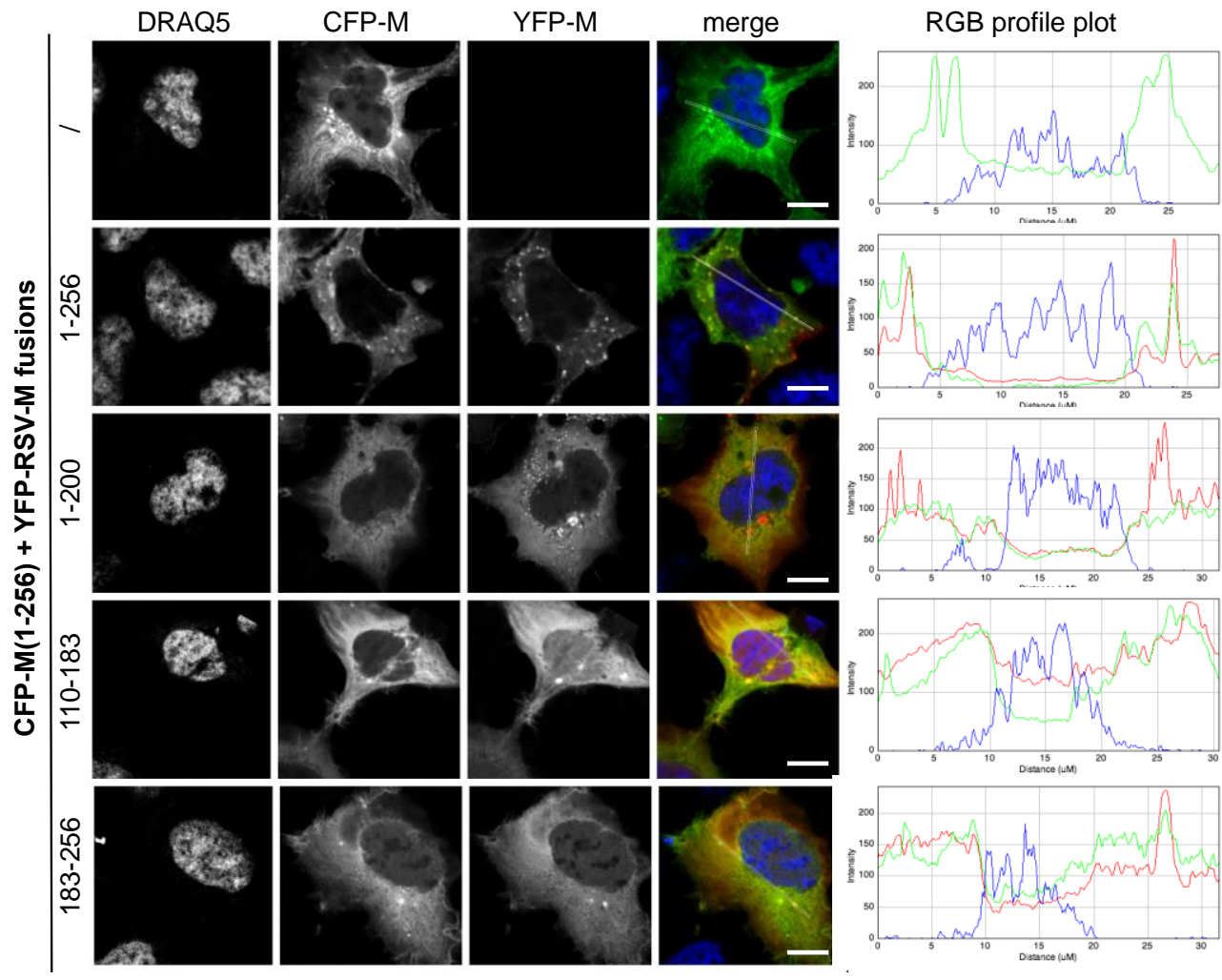

B

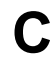

D

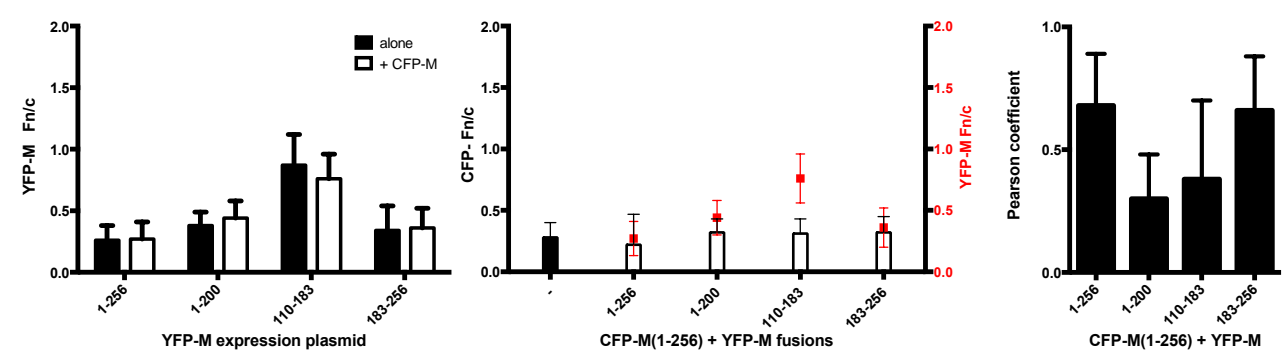

Figure 3. Deletion of N- and C-terminal portions of RSV M affects protein ability to colocalize with full-length protein. (A) HEK293 A cells were transfected to transiently express the CFP-M (1-256) fusion protein either in the absence or in the presence of the indicated YFP-M fusions. $24 \mathrm{~h}$ post transfection cell nuclei were stained with DRAQ5 and cells processed for CSLM analysis. Representative images relative to cell nuclei (DRAQ5), CFP (CFP-M) and YFP-RSV M fusions (YFP-M) are shown, along with merged images of the three channels (merge). A RGB profile plot relative to the section highlighted in the merge channel is shown on the right panels; (B) Digital images such as those shown in (A) were quantitatively analyzed using software ImageJ to calculate the $\mathrm{Fn} / \mathrm{c}$ ratio relative to each of the indicated YFP fusion protein, either expressed alone (black columns) or in the presence of CFP-M (1-256) (white columns). $n \geq 63$ from at least two independent experiments; (C) Digital images such as those shown in (A) were quantitatively analyzed using software Image to calculate the Fn/c ratio relative to CFP-M (1-256), either expressed alone (black columns) or in the presence of (white columns) of each of the indicated YFP fusion protein. Red dots indicate the Fn/c ratio relative to the indicated YFP-M fusions. $n \geq 63$ from at least two independent experiments; (D) Images such as those shown in (A) were used to calculate the Pearson's coefficient relative to each protein pair. $n \geq 19$ from at least two independent experiments. Scale bars represent $20 \mu \mathrm{M}$. 
Furthermore, while clear co-localization between CFP-M (1-256) and YFP-M (1-256) was observed in cytosolic dots (see Figure 3A,D; Pearson 0.68), such phenomena were not observed between CFP-M (1-256) and neither YFP-M (1-200) nor YFP-M (110-183), suggesting that the M deletion mutants tested are not capable of interacting with M (1-256) and affecting its subcellular localization. This hypothesis is also supported by the evidence that these deletions affected the Pearson colocalization coefficient with CFP-M (1-256), although to different extents (Figure 3D). Limited colocalization of YFP-M (183-256) with CFP-M (1-256) was observed in cytosolic dots (Figure 3A, compare the localization of CFP-M and YFP-M in cytosolic dots, bottom images) with a Pearson's coefficient comparable to that between CFP-M (1-256) and YFP-M (1-256) (Figure 3D).

\subsection{RSV M Can Self-Interact in Living Cells}

Our results suggest that deletion of M C- or N-terminal domain affects its ability to self-interact in a cellular context. However, they do not prove that the full-length protein is able to self-interact or that the C-terminal of the protein is able to interact with the full-length protein. Indeed, the co-localization observed between CFP and YFP tagged versions of full-length M may simply reflect the fact that tagging $\mathrm{M}$ with such spontaneously fluorescent proteins does not affect its subcellular localization, so that both CFP- and YFP-tagged version of M localize in the same area of the cell. We directly addressed this issue by bioluminescent energy resonant energy transfer (BRET) assays. To this end, BRET saturation experiments were performed by transfecting HEK293-T with a fixed amount of BRET DONOR plasmid RLuc-M (1-256; $0.5 \mathrm{ng})$ in the presence of increasing amounts of BRET ACCEPTOR plasmid YFP-M (1:256; 0-450 ng). As a positive control and a reference for data normalization, a fusion protein between RLuc and YFP (RLuc-YFP) was also expressed, and RLuc and YFP were individually co-expressed as a negative control (Figure 4A).
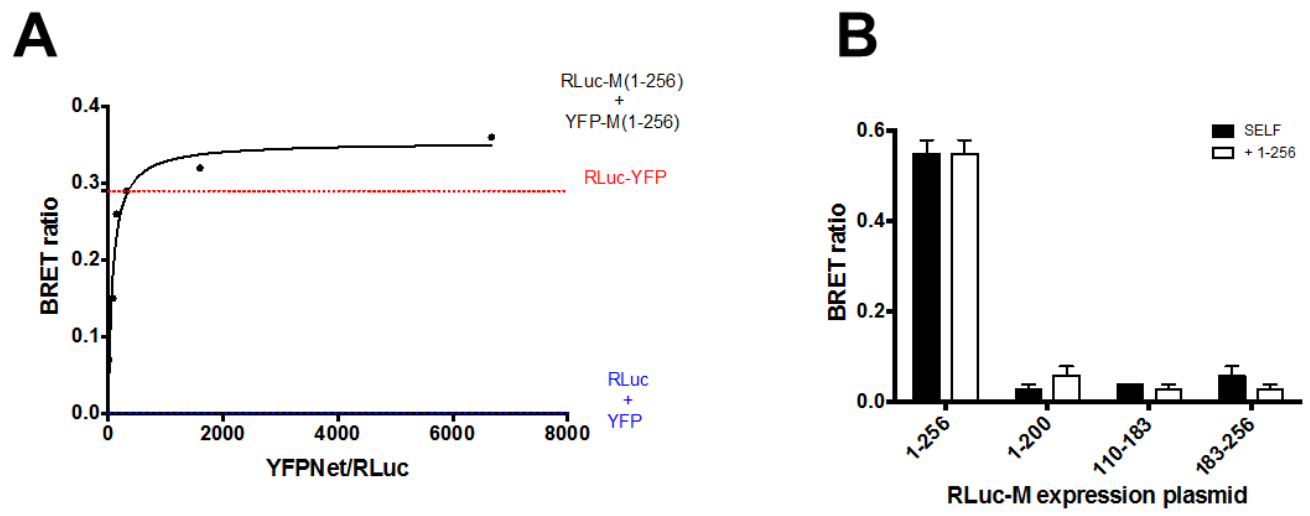

Figure 4. RSV M can self-interact in live Mammalian cells, depending on its $\mathrm{N}$ and C-terminal domains. (A) HEK293T cells were transfected to transiently express the RLuc-M (1-256) plasmid $(0.5 \mathrm{ng})$ either in the absence or in the presence of increasing amounts the YFP-M (1-256) plasmid (range 0-450 ng). Alternatively, cells were transfected with the positive control plasmid RLuc-YFP (225 ng) or with plasmid RLuc-M (1-256) and pCMVFLAG-X-YFP as negative controls. $48 \mathrm{~h}$ later cells were processed for BRET measurements as described in the Materials and Methods section. The BRET ratio relative to the RLuc-M (1-256) and the YFP-M (1-256) BRET pair was plotted against the normalized YFPNet/RLuc ratio, and data used to calculate the Bmax and B50. The red dotted line indicates the BRET ratio obtained for the RLuc-YFP control protein, and the blue dotted line indicates the BRET ratio obtained for the RLuc-M (1-256) protein expressed in the presence of YFP alone. Representative data from four independent experiments are shown; (B) HEK293T cells were transfected to transiently express the RLuc-M expression plasmids either alone or in the presence of the indicated YFP-M expression plasmids. $48 \mathrm{~h}$ later cells were processed for BRET measurements as described in the Materials and Methods section. The BRET ratio relative to each condition is shown. Representative data from two independent experiments are shown. 
At $48 \mathrm{~h}$ post transfection, YFP fluorescent and BRET signals were acquired in living cells, and BRET ratios calculated, as described in the Materials and Methods section. Our results indicate that the RLuc-YFP fusion generated a BRET ratio of $0.34 \pm 0.02$ (Figure 4A), while the RLuc and YFP protein, generated a BRET ratio of 0. Importantly, co-expression of RLuc-M (1-256) and YFP-M (1-256) generated a BRET ratio which rapidly increased with the ratio between YFP-M (1-256) and RLuc-M (1-256) expression levels (Figure 4A), and which quickly reached saturation. Data fitting allowed us to calculate the Bmax, corresponding to the maximal BRET ratio obtainable for the BRET pair $(0.43 \pm 0.04)$ and the $B_{50}$, corresponding to the ratio between YFP-M (1-256) and RLuc-M (1-256) sufficient to generate a BRET ratio corresponding to half of the Bmax (48.4 \pm 13.7$)$. Overall, our results indicate that RLuc-M and YFP-M can interact with high affinity in live mammalian cells.

\subsection{Deletion of N-and C-Terminal Portions of RSV M Affects Protein Ability to Form Dimers in Living Cells}

We next used BRET assays to evaluate the ability of $\mathrm{M}$ deletion mutants to self-interact and to form complexes with the full-length protein. To this end, HEK293-T cells were transfected with a series of plasmids encoding the above described $\mathrm{M}$ deletion mutants fused to RLuc, either in the absence or in the presence of YFP-M expressing plasmids. Each RLuc-M derivative was expressed in the presence of its YFP-tagged version, or in the presence of YFP-M (1-256). $48 \mathrm{~h}$ post transfection cells were processed for BRET assays to monitor protein self-interaction. As expected, we could calculate a strong BRET signal $(0.55 \pm 0.03)$ relative to the RLuc-M (1-256)/YFP-M (1-256) BRET pair (Figure 4B), consistent with the fact that full-length $\mathrm{M}$ is capable of self-interacting in living mammalian cells. However, very weak BRET signals were calculated for the RLuc-M (1-200)/YFP-M (1-200), RLuc-M (110-183)/YFP-M (110-183) and RLuc-M (183-256)/YFP-M (183-256) BRET pairs (0.03, 0.04, 0.06, respectively, see Figure 4B, black bars), indicating both $\mathrm{N}$ - and C-terminal domains of $\mathrm{M}$ are required for homodimerization. Similarly, weak BRET signals were generated when the RLuc deletion mutants were expressed in the presence of full-length YFP-M (1-256), indicating that $\mathrm{N}$ - and C-terminal deletion mutants of $\mathrm{M}$ are not capable of interacting with full-length $\mathrm{M}$ in living cells (Figure 4B, white bars).

\section{Discussion}

The data presented in the current study shows that the RSV M protein can self-interact when expressed in living mammalian cells. Our study confirms in cell culture the self-interaction of $M$, previously shown by a number of studies reporting its ability to form homodimers and higher order oligomers in vitro $[19,28,29]$, highlighting the physiological relevance of the in vitro observations.

Our discovery that this interaction in a cellular context requires both the $\mathrm{N}$ and $\mathrm{C}$ terminal domains of the protein is consistent with a recently reported head to tail dimeric structure of $\mathrm{M}$, whereby the $\mathrm{N}$-terminal domain of one subunit interacts with the C-terminal domain of the other subunit [27], and is in contrast with initially resolved monomeric M structure [26].

When transiently expressed in mammalian cells as YFP-M fusions, full-length $\mathrm{M}$ and its deletion mutants localized to the expected cellular compartment, depending on the presence or the absence of M NES and NLS, thus confirming and validating our previous work defining the nuclear transport motifs of M (see Figure 2; [43,44]). Importantly, YFP-M (1-200), lacking two leucine residues belonging to M NES (residues 194-206), localized significantly more in the nucleus than FL YFP-M. As expected, YFP-M (110-183), lacking the NES but bearing the NLS was present equally within the nucleus and the cytoplasm as has been shown previously, while YFP-M (183-256) that has the NES but lacks the NLS, was cytoplasmic [43].

Subcellular localization and co-localization analysis upon co-expression of CFP-M (1-256) with YFP-M (1-256) or its deletion mutants suggested that CFP-M (1-256) does not likely interact with any of the deletion mutants, with the possible exception of YFP-M (183-256), as indicated by the drop in co-localization (see Figure 3D). Furthermore, the subcellular localization of CFP-M (1-256) and YFP-M (110-183) was not affected upon co-expression, with the former remaining mainly cytosolic and the latter equally distributing between the cytoplasm and the nucleus (see Figure $3 \mathrm{~A}-\mathrm{C}$ ). In contrast, YFP-M 
(183-256) partially co-localized with CFP-M (1-256), thus implying potential interaction between the two proteins. However, the co-localization observed likely reflects their presence in the same location and not necessarily an interaction (see below). Interestingly, YFP-M (1-200) formed cytoplasmic inclusion bodies (IBs) that look very similar to those formed by the CFP-M (1-256), yet when the two proteins were co-expressed, they did not co-localize. Expression of YFP- and CFP- fused deletion mutants also suggested that M (1-200) and M (183-256) may be able to self-interact as they formed IBs when expressed in living cells.

BRET analysis in living cells clearly showed that full-length $\mathrm{M}$ is very effective in forming dimers in living cells (see Figure 4A). However, none of the deletion mutants analyzed in our study were able to self-interact (see Figure 4B). This suggests that the observed IBs are formed due to aggregation that may be brought about by misfolding of the proteins. However, massive misfolding of the $\mathrm{M}$ mutants tested in our study is unlikely, since similar deletion mutants (containing $M$ aas 1-144, 114-256 and 1-110), still interact with viral nucleocapsids to similar levels as the full-length protein [22]. Furthermore, RSV M (110-183) has been shown to inhibit host cell transcription to similar levels as compared to the full-length protein (Ghildyal et al., unpublished observations [45]). Our data is consistent with the M dimer being formed by the head to tail interaction of the subunits. In addition, none of the deletion mutants were able to dimerize with the full-length $\mathrm{M}$ (see Figure 4). This finding is consistent with the structure of the $\mathrm{M}$ dimer, which has a very large interface [27].

The dimerization interface comprises residues 63 to 68,92 to 105,129 to 134, 144, 163, 225 to 235, while residue T205 likely modulates M oligomerization in a phosphorylation dependent manner [27]. Our data shows that all the residues are needed to form a stable dimer, consistent with previous work, which demonstrated that mutation of single residues in the context of the full-length protein has an observable effect on the filament formation and dimerization/oligomerization behavior of $M$ [27]. Clearly, there are complex interactions with several residues in the dimerization interface with each having a specific role in stabilizing the structure. Since point mutations destabilizing RSV M self-interaction in vitro also negatively affected viral budding, it is reasonable to consider $M$ dimerization as an attractive potential target for the development of antiviral agents. In this context, the BRET-based assay described here to monitor M self-interaction might provide a valuable tool for screening of compounds interfering with $\mathrm{M}$ self-interaction, or for the validation of hits identified by other methods [35,46-48].

Acknowledgments: This work was supported by the Ministero dell'Istruzione, Università e Ricerca MURST EX60\% to Gualtiero Alvisi. Plasmid pCDNA3.1-RSV M (1-256), encoding for codon optimized M, was a generous gift from Monika Bajorek (INRA, France).

Author Contributions: Marta Trevisan revised the manuscript and participated to study design, Veronica Di Antonio performed cloning and BRET experiments, Giorgio Palù and Annalisa Radeghieri revised the manuscript, Reena Ghildyal designed the study and wrote the manuscript Gualtiero Alvisi designed the study, performed imaging experiments, and wrote the manuscript.

Conflicts of Interest: The authors declare no conflict of interest.

\section{References}

1. Stein, R.T.; Bont, L.J.; Zar, H.; Polack, F.P.; Park, C.; Claxton, A.; Borok, G.; Butylkova, Y.; Wegzyn, C. Respiratory syncytial virus hospitalization and mortality: Systematic review and meta-analysis. Pediatr. Pulmonol. 2017, 52, 556-569. [CrossRef] [PubMed]

2. Paes, B.; Fauroux, B.; Figueras-Aloy, J.; Bont, L.; Checchia, P.A.; Simoes, E.A.; Manzoni, P.; Carbonell-Estrany, X. Defining the risk and associated morbidity and mortality of severe respiratory syncytial virus infection among infants with chronic lung disease. Infect. Dis. Ther. 2016, 5, 453-471. [CrossRef] [PubMed]

3. Figueras-Aloy, J.; Manzoni, P.; Paes, B.; Simoes, E.A.; Bont, L.; Checchia, P.A.; Fauroux, B.; Carbonell-Estrany, X. Defining the risk and associated morbidity and mortality of severe respiratory syncytial virus infection among preterm infants without chronic lung disease or congenital heart disease. Infect. Dis. Ther. 2016, 5, 417-452. [CrossRef] [PubMed] 
4. Higgins, D.; Trujillo, C.; Keech, C. Advances in RSV vaccine research and development-A global agenda. Vaccine 2016, 34, 2870-2875. [CrossRef] [PubMed]

5. Lozano, S.; Halm-Lemeille, M.P.; Lepailleur, A.; Rault, S.; Bureau, R. Consensus QSAR related to global or moa models: Application to acute toxicity for fish. Mol. Inform. 2010, 29, 803-813. [CrossRef] [PubMed]

6. Nair, H.; Nokes, D.J.; Gessner, B.D.; Dherani, M.; Madhi, S.A.; Singleton, R.J.; O’Brien, K.L.; Roca, A.; Wright, P.F.; Bruce, N.; et al. Global burden of acute lower respiratory infections due to respiratory syncytial virus in young children: A systematic review and meta-analysis. Lancet 2010, 375, 1545-1555. [CrossRef]

7. Branche, A.R.; Falsey, A.R. Respiratory syncytial virus infection in older adults: An under-recognized problem. Drugs Aging 2015, 32, 261-269. [CrossRef] [PubMed]

8. Griffiths, C.; Drews, S.J.; Marchant, D.J. Respiratory syncytial virus: Infection, detection, and new options for prevention and treatment. Clin. Microbiol. Rev. 2017, 30, 277-319. [CrossRef] [PubMed]

9. Afonso, C.L.; Amarasinghe, G.K.; Banyai, K.; Bao, Y.; Basler, C.F.; Bavari, S.; Bejerman, N.; Blasdell, K.R.; Briand, F.X.; Briese, T.; et al. Taxonomy of the order mononegavirales: Update 2016. Arch. Virol. 2016, 161, 2351-2360. [CrossRef] [PubMed]

10. Boyapalle, S.; Wong, T.; Garay, J.; Teng, M.; San Juan-Vergara, H.; Mohapatra, S.; Mohapatra, S. Respiratory syncytial virus NS1 protein colocalizes with mitochondrial antiviral signaling protein MAVS following infection. PLoS ONE 2012, 7, e29386. [CrossRef] [PubMed]

11. Teng, M.N.; Whitehead, S.S.; Bermingham, A.; St Claire, M.; Elkins, W.R.; Murphy, B.R.; Collins, P.L. Recombinant respiratory syncytial virus that does not express the NS1 or M2-2 protein is highly attenuated and immunogenic in chimpanzees. J. Virol. 2000, 74, 9317-9321. [CrossRef] [PubMed]

12. Ling, Z.; Tran, K.C.; Teng, M.N. Human respiratory syncytial virus nonstructural protein NS2 antagonizes the activation of beta interferon transcription by interacting with RIG-I. J. Virol. 2009, 83, 3734-3742. [CrossRef] [PubMed]

13. Whitehead, S.S.; Bukreyev, A.; Teng, M.N.; Firestone, C.Y.; St Claire, M.; Elkins, W.R.; Collins, P.L.; Murphy, B.R. Recombinant respiratory syncytial virus bearing a deletion of either the NS2 or SH gene is attenuated in chimpanzees. J. Virol. 1999, 73, 3438-3442. [PubMed]

14. Teng, M.N.; Collins, P.L. Altered growth characteristics of recombinant respiratory syncytial viruses which do not produce NS2 protein. J. Virol. 1999, 73, 466-473. [PubMed]

15. Collins, P.L.; Crowe, J.E.J. Respiratory syncytial virus and metapneumovirus. In Fields Virology, 5th ed.; Knipe, D.M., Howley, P.M., Griffin, D.E., Lamb, R.A., Martin, M.A., Roizman, B., Straus, S.E., Eds.; Lippincott Williams \& Wilkins: Philadelphia, PA, USA, 2007; pp. 1601-1646.

16. El Najjar, F.; Schmitt, A.P.; Dutch, R.E. Paramyxovirus glycoprotein incorporation, assembly and budding: A three way dance for infectious particle production. Viruses 2014, 6, 3019-3054. [CrossRef] [PubMed]

17. Ghildyal, R.; Jans, D.A.; Bardin, P.G.; Mills, J. Protein-protein interactions in RSV assembly: Potential targets for attenuating rsv strains. Infect. Disord. Drug Targets 2012, 12, 103-109. [CrossRef] [PubMed]

18. Ghildyal, R.; Li, D.; Peroulis, I.; Shields, B.; Bardin, P.G.; Teng, M.N.; Collins, P.L.; Meanger, J.; Mills, J. Interaction between the respiratory syncytial virus $\mathrm{G}$ glycoprotein cytoplasmic domain and the matrix protein. J. Gen. Virol. 2005, 86, 1879-1884. [CrossRef] [PubMed]

19. Henderson, G.; Murray, J.; Yeo, R.P. Sorting of the respiratory syncytial virus matrix protein into detergent-resistant structures is dependent on cell-surface expression of the glycoproteins. Virology 2002, 300, 244-254. [CrossRef] [PubMed]

20. Meshram, C.D.; Baviskar, P.S.; Ognibene, C.M.; Oomens, A.G. The respiratory syncytial virus phosphoprotein, matrix protein, and fusion protein carboxy-terminal domain drive efficient filamentous virus-like particle formation. J. Virol. 2016, 90, 10612-10628. [CrossRef] [PubMed]

21. Ghildyal, R.; Mills, J.; Murray, M.; Vardaxis, N.; Meanger, J. Respiratory syncytial virus matrix protein associates with nucleocapsids in infected cells. J. Gen. Virol. 2002, 83, 753-757. [CrossRef] [PubMed]

22. Li, D.; Jans, D.A.; Bardin, P.G.; Meanger, J.; Mills, J.; Ghildyal, R. Association of respiratory syncytial virus $\mathrm{m}$ protein with viral nucleocapsids is mediated by the M2-1 protein. J. Virol. 2008, 82, 8863-8870. [CrossRef] [PubMed]

23. Ray, G.; Schmitt, P.T.; Schmitt, A.P. C-terminal DXD-containing sequences within paramyxovirus nucleocapsid proteins determine matrix protein compatibility and can direct foreign proteins into budding particles. J. Virol. 2016, 90, 3650-3660. [CrossRef] [PubMed] 
24. Kiss, G.; Holl, J.M.; Williams, G.M.; Alonas, E.; Vanover, D.; Lifland, A.W.; Gudheti, M.; Guerrero-Ferreira, R.C.; Nair, V.; Yi, H.; et al. Structural analysis of respiratory syncytial virus reveals the position of M2-1 between the matrix protein and the ribonucleoprotein complex. J. Virol. 2014, 88, 7602-7617. [CrossRef] [PubMed]

25. Marty, A.; Meanger, J.; Mills, J.; Shields, B.; Ghildyal, R. Association of matrix protein of respiratory syncytial virus with the host cell membrane of infected cells. Arch. Virol. 2004, 149, 199-210. [CrossRef] [PubMed]

26. Money, V.A.; McPhee, H.K.; Mosely, J.A.; Sanderson, J.M.; Yeo, R.P. Surface features of a mononegavirales matrix protein indicate sites of membrane interaction. Proc. Natl. Acad. Sci. USA 2009, 106, 4441-4446. [CrossRef] [PubMed]

27. Forster, A.; Maertens, G.N.; Farrell, P.J.; Bajorek, M. Dimerization of matrix protein is required for budding of respiratory syncytial virus. J. Virol. 2015, 89, 4624-4635. [CrossRef] [PubMed]

28. Bajorek, M.; Caly, L.; Tran, K.C.; Maertens, G.N.; Tripp, R.A.; Bacharach, E.; Teng, M.N.; Ghildyal, R.; Jans, D.A. The Thr205 phosphorylation site within respiratory syncytial virus matrix (M) protein modulates m oligomerization and virus production. J. Virol. 2014, 88, 6380-6393. [CrossRef] [PubMed]

29. McPhee, H.K.; Carlisle, J.L.; Beeby, A.; Money, V.A.; Watson, S.M.; Yeo, R.P.; Sanderson, J.M. Influence of lipids on the interfacial disposition of respiratory syncytical virus matrix protein. Langmuir 2011, 27, 304-311. [CrossRef] [PubMed]

30. Leyrat, C.; Renner, M.; Harlos, K.; Huiskonen, J.T.; Grimes, J.M. Structure and self-assembly of the calcium binding matrix protein of human metapneumovirus. Structure 2014, 22, 136-148. [CrossRef] [PubMed]

31. Dessen, A.; Forest, E.; Volchkov, V.; Dolnik, O.; Klenk, H.D.; Weissenhorn, W. Crystallization and preliminary X-ray analysis of the matrix protein from Ebola virus. Acta Crystallogr. D Biol. Crystallogr. 2000, 56, 758-760. [CrossRef] [PubMed]

32. Neumann, P.; Lieber, D.; Meyer, S.; Dautel, P.; Kerth, A.; Kraus, I.; Garten, W.; Stubbs, M.T. Crystal structure of the borna disease virus matrix protein (BDV-M) reveals ssrna binding properties. Proc. Natl. Acad. Sci. USA 2009, 106, 3710-3715. [CrossRef] [PubMed]

33. Battisti, A.J.; Yoder, J.D.; Plevka, P.; Winkler, D.C.; Prasad, V.M.; Kuhn, R.J.; Frey, T.K.; Steven, A.C.; Rossmann, M.G. Cryo-electron tomography of rubella virus. J. Virol. 2012, 86, 11078-11085. [CrossRef] [PubMed]

34. Alvisi, G.; Avanzi, S.; Musiani, D.; Camozzi, D.; Leoni, V.; Ly-Huynh, J.D.; Ripalti, A. Nuclear import of HSV-1 DNA polymerase processivity factor UL42 is mediated by a C-terminally located bipartite nuclear localization signal. Biochemistry 2008, 47, 13764-13777. [CrossRef] [PubMed]

35. Scaturro, P.; Trist, I.M.; Paul, D.; Kumar, A.; Acosta, E.G.; Byrd, C.M.; Jordan, R.; Brancale, A.; Bartenschlager, R. Characterization of the mode of action of a potent dengue virus capsid inhibitor. J. Virol. 2014, 88, 11540-11555. [CrossRef] [PubMed]

36. Sinigalia, E.; Alvisi, G.; Mercorelli, B.; Coen, D.M.; Pari, G.S.; Jans, D.A.; Ripalti, A.; Palu, G.; Loregian, A. Role of homodimerization of human cytomegalovirus DNA polymerase accessory protein UL44 in origin-dependent DNA replication in cells. J. Virol. 2008, 82, 12574-12579. [CrossRef] [PubMed]

37. Paolini, L.; Radeghieri, A.; Civini, S.; Caimi, L.; Ricotta, D. The epsilon hinge-ear region regulates membrane localization of the AP-4 complex. Traffic 2011, 12, 1604-1619. [CrossRef] [PubMed]

38. Alvisi, G.; Roth, D.M.; Camozzi, D.; Pari, G.S.; Loregian, A.; Ripalti, A.; Jans, D.A. The flexible loop of the human cytomegalovirus DNA polymerase processivity factor ppUL44 is required for efficient DNA binding and replication in cells. J. Virol. 2009, 83, 9567-9576. [CrossRef] [PubMed]

39. Ruggieri, A.; Dazert, E.; Metz, P.; Hofmann, S.; Bergeest, J.P.; Mazur, J.; Bankhead, P.; Hiet, M.S.; Kallis, S.; Alvisi, G.; et al. Dynamic oscillation of translation and stress granule formation mark the cellular response to virus infection. Cell Host Microbe 2012, 12, 71-85. [CrossRef] [PubMed]

40. Avanzi, S.; Leoni, V.; Rotola, A.; Alviano, F.; Solimando, L.; Lanzoni, G.; Bonsi, L.; Di Luca, D.; Marchionni, C.; Alvisi, G.; et al. Susceptibility of human placenta derived mesenchymal stromal/stem cells to human herpesviruses infection. PLoS ONE 2013, 8, e71412. [CrossRef] [PubMed]

41. Alvisi, G.; Marin, O.; Pari, G.; Mancini, M.; Avanzi, S.; Loregian, A.; Jans, D.A.; Ripalti, A. Multiple phosphorylation sites at the C-terminus regulate nuclear import of HCMV DNA polymerase processivity factor PPUL44. Virology 2011, 417, 259-267. [CrossRef] [PubMed] 
42. Pettersen, E.F.; Goddard, T.D.; Huang, C.C.; Couch, G.S.; Greenblatt, D.M.; Meng, E.C.; Ferrin, T.E. Ucsf chimera-A visualization system for exploratory research and analysis. J. Comput. Chem. 2004, 25, 1605-1612. [CrossRef] [PubMed]

43. Ghildyal, R.; Ho, A.; Dias, M.; Soegiyono, L.; Bardin, P.G.; Tran, K.C.; Teng, M.N.; Jans, D.A. The respiratory syncytial virus matrix protein possesses a CRM1-mediated nuclear export mechanism. J. Virol. 2009, 83, 5353-5362. [CrossRef] [PubMed]

44. Ghildyal, R.; Ho, A.; Wagstaff, K.M.; Dias, M.M.; Barton, C.L.; Jans, P.; Bardin, P.; Jans, D.A. Nuclear import of the respiratory syncytial virus matrix protein is mediated by importin $\beta 1$ independent of importin $\alpha$. Biochemistry 2005, 44, 12887-12895. [CrossRef] [PubMed]

45. Ghildyal, R.; University of Canberra, Canberra, Australia. In vitro transcription assay showing the inhibition of transcription by full length M, and M (110-183). 2012.

46. Bacart, J.; Corbel, C.; Jockers, R.; Bach, S.; Couturier, C. The BRET technology and its application to screening assays. Biotechnol. J. 2008, 3, 311-324. [CrossRef] [PubMed]

47. Corbel, C.; Wang, Q.; Bousserouel, H.; Hamdi, A.; Zhang, B.; Lozach, O.; Ferandin, Y.; Tan, V.B.; Gueritte, F.; Colas, P.; et al. First BRET-based screening assay performed in budding yeast leads to the discovery of CDK5/p25 interaction inhibitors. Biotechnol. J. 2011, 6, 860-870. [CrossRef] [PubMed]

48. Heding, A. Use of the BRET 7TM receptor/ $\beta$-arrestin assay in drug discovery and screening. Expert Rev. Mol. Diagn. 2004, 4, 403-411. [CrossRef] [PubMed]

(C) 2018 by the authors. Licensee MDPI, Basel, Switzerland. This article is an open access article distributed under the terms and conditions of the Creative Commons Attribution (CC BY) license (http://creativecommons.org/licenses/by/4.0/). 